\title{
Pharmacological and Toxicological Threshold of Bisammonium Tetrakis 4-( $N, N$-Dimethylamino)pyridinium Decavanadate in a Rat Model of Metabolic Syndrome and Insulin Resistance
}

\author{
Samuel Treviño, ${ }^{1}$ Alfonso Díaz, ${ }^{1}$ Eduardo Sánchez-Lara, ${ }^{2}$ \\ Víctor Enrique Sarmiento-Ortega, ${ }^{1}$ José Ángel Flores-Hernández, ${ }^{1}$ Eduardo Brambila $\mathbb{D}^{\mathbb{D}},{ }^{1}$ \\ Francisco J. Meléndez, ${ }^{1}$ and Enrique González-Vergara ${ }^{2}{ }^{2}$ \\ ${ }^{1}$ Facultad de Ciencias Químicas, Benemérita Universidad Autónoma de Puebla, 14 Sur y Av. San Claudio, Col. San Manuel, \\ 72570 Puebla, PUE, Mexico \\ ${ }^{2}$ Centro de Química, ICUAP, Benemérita Universidad Autónoma de Puebla, 14 Sur y Av. San Claudio, Col. San Manuel, \\ 72570 Puebla, PUE, Mexico
}

Correspondence should be addressed to Enrique González-Vergara; enrique.gonzalez@correo.buap.mx

Received 9 March 2018; Revised 6 April 2018; Accepted 18 April 2018; Published 19 June 2018

Academic Editor: Zhe Liu

Copyright (c) 2018 Samuel Treviño et al. This is an open access article distributed under the Creative Commons Attribution License, which permits unrestricted use, distribution, and reproduction in any medium, provided the original work is properly cited.

\begin{abstract}
Vanadium(IV/V) compounds have been studied as possible metallopharmaceutical drugs against diabetes mellitus. However, mechanisms of action and toxicological threshold have been tackled poorly so far. In this paper, our purposes were to evaluate the metabolic activity on dyslipidemia and dysglycemia, insulin signaling in liver and adipose tissue, and toxicology of the title compound. To do so, the previously reported bisammonium tetrakis 4 -( $N, N$-dimethylamino)pyridinium decavanadate, the formula of which is [DMAPH $]_{4}\left(\mathrm{NH}_{4}\right)_{2}\left[\mathrm{~V}_{10} \mathrm{O}_{28}\right] \cdot 8 \mathrm{H}_{2} \mathrm{O}$ (where DMAPH is 4-dimethylaminopyridinium ion), was synthesized, and its doseresponse curve on hyperglycemic rats was evaluated. A Long-Evans rat model showing dyslipidemia and dysglycemia with parameters that reproduce metabolic syndrome and severe insulin resistance was generated. Two different dosages, $5 \mu \mathrm{mol}$ and $10 \mu \mathrm{mol}$ twice a week of the title compound (equivalent to $2.43 \mathrm{mg} \cdot \mathrm{V} / \mathrm{kg} / \mathrm{day}$ and $4.86 \mathrm{mg} \cdot \mathrm{V} / \mathrm{kg} / \mathrm{day}$, resp.), were administered intraperitoneal (i.p.) for two months. Then, an improvement on each of the following parameters was observed at a $5 \mu$ mol dose: weight reduction, abdominal perimeter, fatty index, body mass index, oral glucose tolerance test, lipid profile, and adipokine and insulin resistance indexes. Nevertheless, when the toxicological profile was evaluated at a $10 \mu \mathrm{mol}$ dose, it did not show complete improvement, tested by the liver and adipose histology, as well as by insulin receptor phosphorylation and GLUT-4 expression. In conclusion, the title compound administration produces regulation on lipids and carbohydrates, regardless of dose, but the pharmacological and toxicological threshold for cell regulation are suggested to be up to $5 \mu \mathrm{mol}(2.43 \mathrm{mg} \cdot \mathrm{V} / \mathrm{kg} / \mathrm{day})$ dose twice per week.
\end{abstract}

\section{Introduction}

Interest in vanadium actions on biological systems has gradually increased, and its physiological relevance has been established in recent years $[1,2]$. Vanadium is the 18 th most abundant element in the crust of our planet, even more than zinc $(0.019 \%$ and $0.008 \%$, resp.). Regarding this occurrence, vanadium is present in the soil, water, and air, in almost all types of ecosystems. It is absorbed by plants and travels along the food chain up to humans; thus, it is distributed ubiquitously in living organisms [1-3]. However, metabolism of vanadium in humans and animals has not been fully understood, and evidence is not conclusive as to its importance as a trace element [4]. The estimated daily consumption ranges from 10 to $60 \mu \mathrm{g}$ depending on a mammal's diet, but its deficiency in mammals inhibits growth, impairs cellular regenerative functions, and affects thyroid metabolism and bone mineralization, and it causes disturbances in lipid and carbohydrate balance [3-6]. 
Lipid and carbohydrate disorders are strongly linked to obesity development, insulin resistance, type 2 diabetes, dyslipidemia, hepatic steatosis, and cardiovascular diseases. All of which have become known as metabolic syndrome. Metabolic syndrome is a major public health problem and an important clinical challenge worldwide because of its prevalence in 10 to $84 \%$ of the population depending on the world region. The International Diabetes Federation estimates that one-quarter of the world's adult population suffers from metabolic syndrome associated with being overweight and an increased body mass index that is reflected in a higher fatty body mass, distributed mainly in the visceral adipose tissue (abdominal circumference) [7-10]. Despite many years of research and partial success in the treatment of metabolic diseases, molecular mechanisms and their accompanying subcellular changes have not been fully elucidated. Therefore, research has focused on less invasive and more effective methods of treatment. Over the last twenty years of research, vanadium compounds have been shown to act in a similar way to insulin on selected diabetes and metabolic syndrome models, in tests both on animals and humans as far as physiological symptoms and biochemical parameters are concerned [11-13].

Depending on its speciation forms, physicochemical properties, and concentration, vanadium can be absorbed and distributed into the body. Most vanadium complexes are transformed into a cationic form (vanadyl) which binds to transferrin or albumin, where it can go through spontaneous oxidation to become vanadate [14]. Vanadate(V) and vanadyl(IV) are easily redox interconvertible, but vanadate is the main inorganic vanadium species available for interaction with cellular functions [2, 15-17]. The oxidation state of vanadium is a factor that determines its biological effects, which are present in the activity regulation of many enzymes and phosphorylation and dephosphorylation processes. In enzymes, regulatory properties of vanadate depend, at least in part, on its esterification with phosphate [18]. Therefore, enzymes can accept vanadate as an analogy to phosphate [19-21]. However, there is a subtle tight threshold between biological activity and toxicity that is correlated to its degree of oxidation (vanadyl $<$ vanadate ion) and chemical form (organic < inorganic) [3, 21-23]. In this respect, the most often observed side effects include a loss of appetite and significant reduction of body weight (often leading to anorexia), as well as a low activity of hepatic damage enzymes, confirmed by histopathological studies [24]. However, reports are limited and divergent, but it has been suggested that vanadium toxicity is dependent on speciation and oxidation state via time and doses of administration. The therapeutic concentration limit of vanadium compounds is, as a general rule, below $0.01 \times 10^{-3} \mathrm{M}$, which is a safe limit and maintains the biological activity, whereas several toxic effects associated with its threshold or accumulation in tissues may be expected to be above $1.0 \times 10^{-3} \mathrm{M}$ [25]. Regarding vanadium toxicity, it has been shown that it is dramatically reduced when oligomerized in the form of decavanadate [20-23]. The biochemical importance of decavanadate resides in protein-bound species because it is very stable to $\mathrm{pH}$ changes and is eventually turned to labile oxovanadate species. Thus, its rate of disgregation can be very slow but effective, which allows it to exist under physiological conditions for some time [21]. Likewise, decavanadate is an anion that could get into the cell across proteins like channels or lipid interactions to trigger its biological effects on energy transduction systems [26]. Recently, our working team reported a decavanadate compound with DMAPH. The crystal structure of this complex has been completely characterized [27]. Thus, in this study, our aim was to evaluate the possible metabolic activity of the compound in a dyslipidemia and dysglycemia model, related to insulin signaling in liver and adipose tissue, as well as its toxicological and pharmacological effects.

\section{Materials and Methods}

2.1. Synthesis of $[\mathrm{DMAPH}]_{4}\left(\mathrm{NH}_{4}\right)_{2}\left[\mathrm{~V}_{10} \mathrm{O}_{28}\right] \cdot 8 \mathrm{H}_{2} \mathrm{O}$ (V10$D M A P)$. All chemicals used were of reagent grade and were purchased from Sigma-Aldrich. The synthesis was performed with a $0.468 \mathrm{~g}(4 \mathrm{mmol})$ mixture of ammonium metavanadate in $18 \mathrm{~mL}$ of distilled water in an Erlenmeyer flask with magnetic stirring and heated at $70^{\circ} \mathrm{C}$ until it was dissolved. Then, four drops of concentrated hydrochloric acid $(37 \%)$ at room temperature were added to allow decavanadate anion formation at $\mathrm{pH}$. After obtaining an orange solution from this process, $0.122 \mathrm{~g}(1 \mathrm{mmol})$ of 4 dimethylaminopyridine dissolved in $2 \mathrm{~mL}$ of distilled water was added dropwise. Once 4-dimethylaminopyridine was added, the mixture was filtered off and allowed to stand at room temperature for one day to produce orange crystals of the title compound [27].

2.2. Dose-Response Curve of V10-DMAP. Long-Evans rats were used in this study because this strain is twice as susceptible to spontaneously develop obesity and hyperglycemia. Thirty male rats weighing 300 to $320 \mathrm{~g}$ underwent an intraperitoneal application of alloxan $(150 \mathrm{mg} / \mathrm{kg})$ to induce hyperglycemia. When hyperglycemia (HG) above $200 \mathrm{mg} / \mathrm{dL}$ was present, animals were split into six working groups $(n=5)$, all of which were given with dosages of the title compound abbreviated as V10-DMAP from now on, at $0 \mu \mathrm{mol}, 2.5 \mu \mathrm{mol}, 5 \mu \mathrm{mol}, 7.5 \mu \mathrm{mol}, 10 \mu \mathrm{mol}$, and $20 \mu \mathrm{mol}$, dissolved in $1 \mathrm{~mL}$ of injectable solution to be administered via intraperitoneal (i.p.). These dosages were administered twice a week for a month until glucose was normalized $(\leq 130 \mathrm{mg} / \mathrm{dL})$. Monitoring was carried out with serum collected in a BD Vacutainer ${ }^{\circledR}$ venous blood collection system, centrifuged at $2500 \mathrm{rpm}$ for $5 \mathrm{~min}$. Glucose quantification was carried out with a commercial kit, and the values obtained were used to determine a dose-response curve.

2.3. Dyslipidemia and Dysglycemia Model. Forty male Long-Evans rats (70-100 g) were provided by the vivarium "Claude Bernard" from Benemérita Universidad Autónoma de Puebla. The rats were housed in a climate-controlled environment and $12 \mathrm{~h}$ light-dark cycles with free access to food and water ad libitum. All procedures described in this 
study agreed with the Guide for the Care and Use of Laboratory Animals of the Mexican Council for Animal Care NOM-062-ZOO-1999. All applicable international, national, and institutional guidelines for the care and use of animals were followed. The rats were conditioned with a normal calorie diet during 15 days. The diet used was 5001 from LabDiet (Laboratory Rodent Diet), and its composition can be accessed on the manufacturer's website. Upon reaching the ideal weight $(150 \mathrm{~g})$, animals were randomly split into different groups. Two groups were formed: group 1: normal calorie or NC group fed with 5001 from LabDiet $(n=10)$; group 2: high calorie or HC group fed with 5008 from LabDiet $(n=30)$ Diet 5001 from LabDiet provides $58.0 \%$ carbohydrates, $13.5 \%$ fat, and $28.5 \%$ proteins. Diet 5008 from LabDiet provides $56.44 \%$ carbohydrates, $17.0 \%$ fat, and $26.85 \%$ proteins. The groups were fed for two months ad libitum with diet 5001 as a caloric control and diet 5008 until they developed the dyslipidemia and dysglycemia model. The model was validated by measuring body weight, abdominal perimeter, and tip of the nose to base of the tail length. BMI (body mass index) and body fat percentage were determined by the Lee index [28]. Glucose, fructosamine, triglycerides, total cholesterol, HDL cholesterol, insulin, and insulin resistance by a homeostasis model assessment insulin resistance (HOMA-IR) and insulin resistance adipocyte dysfunction (IDA-IR) were biochemically evaluated [28].

\subsection{Effect of V10-DMAP on Dyslipidemia and Dysglycemia} Model. After appearance of the metabolic dysregulation validation, two groups of 10 rats from the 5008 group were randomly separated and divided into groups 3 and 4 as follows: group 3: HC-V10-DMAP-5 $\mu$ mol group fed with diet 5008 and administered twice a week (i.p.) $(n=10)$; group 4: HC-V10-DMAP-10 $\mu$ mol group was fed with diet 5008 and administered twice a week (i.p.) $(n=10)$. Both groups were fed for a period of two more months. The zoometry was monitored every two weeks for two months as described above. Toxicological and biochemical parameters in fasting conditions were assessed in serum at the end of the experimental period: total bilirubin, aspartate aminotransferase (AST), alanine aminotransferase (ALT), glutamyl transpeptidase (GT), lactate dehydrogenase (LDH), glucose, insulin, leptin, adiponectin, fructosamine, triglycerides, free fatty acids, total cholesterol, and HDL cholesterol were determined by using commercial kits. Additionally, an oral glucose tolerance test (OGTT, $1.75 \mathrm{~g}$ of glucose anhydrous $/ \mathrm{kg}$ ) was carried out after $4-6 \mathrm{~h}$ of fasting. A postload monitoring was carried out at 30,60 , and $90 \mathrm{~min}$, and the area under the curve (AUC) was calculated. The samples were taken by cardiac puncture after anesthesia with ketamine and xylazine $(20 / 137 \mathrm{mg} / \mathrm{kg}$ ). Insulin resistance indexes (HOMA-IR and IDA-IR) were calculated.

2.5. Effects of V10-DMAP on the Liver and Adipose Tissue. One week after the last biochemical evaluation, rats were anesthetized with sodium pentobarbital $(40 \mathrm{mg} / \mathrm{kg}$, i.p.) and then perfused with $200 \mathrm{~mL}$ of $4 \%$ paraformaldehyde. Biopsies from liver and visceral white adipose tissue were removed and postfixed in the same solution for $48 \mathrm{~h}$ and then embedded in paraffin. Sections of $5 \mu \mathrm{m}$ thick were taken from each tissue for subsequent staining. Histological evaluation was carried out with hematoxylin-eosin stain using standard procedures after paraffin removal and tissue rehydration. The degree of hepatic injury and adipose tissue remodeling (hypertrophy) were evaluated with light microscopy. Additionally, sections of tissue were rehydrated according to conventional histological techniques; then, nonspecific binding sites were blocked by incubation in $2 \%$ IgG-free bovine serum albumin (BSA, Sigma). After that, specimens were incubated with $0.2 \%$ Triton X-100. The sections were incubated overnight at 4 to $8^{\circ} \mathrm{C}$ with primary antibodies: $p$-insulin $\mathrm{R} \beta$ Antibody (Tyr 1162/1163) to the liver and adipose tissue and GLUT-4 to adipose tissue. The primary antibodies (Santa Cruz Biotechnology Inc., CA, USA) were $1: 100$ diluted. Fluorescein isothiocyanate (FITC) secondary antibodies $(1: 100$, Jackson ImmunoResearch Laboratories Inc., PA, USA) revealed absence or presence of proteins. Slides were mounted with VectaShield containing 4',6-diamidino-2-phenylindole (DAPI) (Vector Labs., CA, USA) for nucleus staining. Photomicrographs were taken using a fluorescence microscope (Leica Microsystems $\mathrm{GmbH}$, Wetzlar, Germany) and projected with a Leica IM1000 version 1.20 release-9 computer-based program (Imagic Bildverarbeitung AG, Leica Microsystems, Heerbrugg, Switzerland).

2.6. Statistical Analysis. Results were expressed as a mean \pm standard error of the mean (SEM). A dietary comparison was performed by Student's $t$-test, considered significant $p \leq 0.05$. Meanwhile, a comparison of the groups studied after (V10-DMAP) treatments was performed by an analysis of variance and multiple comparisons using a two-way ANOVA analysis and a Bonferroni post hoc test, obtaining a significant $p<0.05$. A GraphPad Prism 5.0 statistical program was used to perform this analysis.

\section{Results}

Hyperglycemic rats induced by alloxan initially showed an average of serum glucose of $300 \mathrm{mg} / \mathrm{dL}$. The V10-DMAP dosages administrated twice a week for one month period produced a decrease in glucose levels depending on the vanadium compound concentration. According to the results, doses of $5 \mu \mathrm{mol}$ and $10 \mu \mathrm{mol}$ of the title compound (equivalent to $2.43 \mathrm{mg} \cdot \mathrm{V} / \mathrm{kg} /$ day and $4.86 \mathrm{mg} \cdot \mathrm{V} / \mathrm{kg} /$ day, resp.) twice a week, reduced glucose levels below $130 \mathrm{mg} / \mathrm{dL}$ in $50 \%$ of the subjects given with this compound (Figure 1). To determine the effective dose $50\left(\mathrm{ED}_{50}\right)$, we proceeded to perform a mathematical model to apply the exact concentration. Because the mathematical model did not discriminate between 5, 7.5, and $10 \mu \mathrm{mol}$ doses, we decided to use only two different doses ( $5 \mu \mathrm{mol}$ and $10 \mu \mathrm{mol}$, equivalent to $2.43 \mathrm{mg} \cdot \mathrm{V} / \mathrm{kg} /$ day and $4.86 \mathrm{mg} \cdot \mathrm{V} / \mathrm{kg} /$ day, resp.) in later experiments of metabolic regulation to investigate their toxicological effects.

On the contrary, in the model of dyslipidemia and dysglycemia produced by one-month consumption of diet 


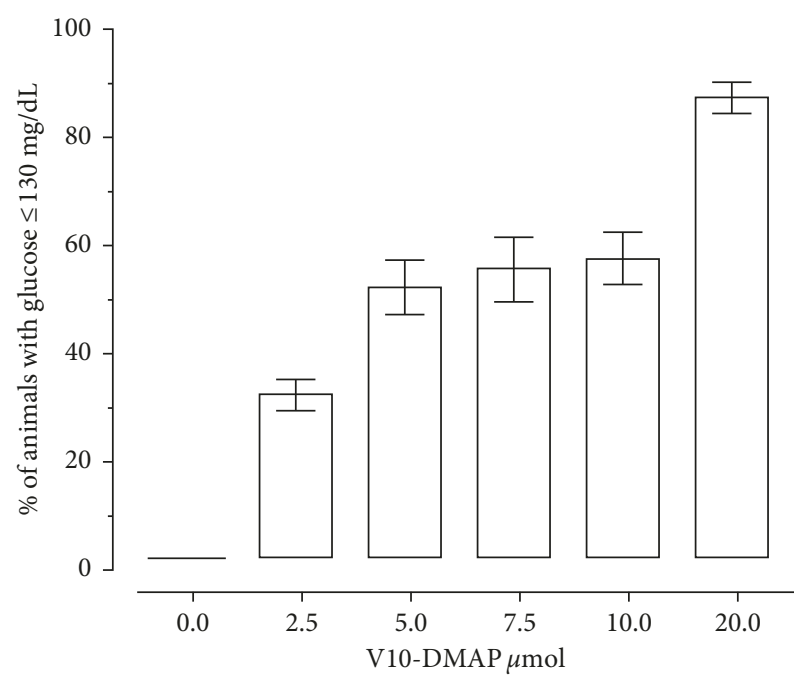

FIgURE 1: Effective dose 50 analysis $\left(\mathrm{ED}_{50}\right)$. The figure represents the percentage of glucose level reduction $\leq 130 \mathrm{mg} / \mathrm{dL}$ by administration of V10-DMAP. The hyperglycemic Long-Evans rats ( $n=5$ /group) were given with dosages of $0.0,2.5,5.0,7.5,10.0$, and $20 \mu \mathrm{mol}$ of V10-DMAP for four weeks. The Long-Evans rats were alloxan-induced hyperglycemic $(150 \mathrm{mg} / \mathrm{kg})$. Mean glucose before V10-DMAP administration was $\approx 300 \mathrm{mg} / \mathrm{dL}$.

5008 (which possesses $3.5 \%$ more fat than the normal-caloric diet 5001), there was a Long-Evans rat weight increase. Also, there was an elevation in the levels of glucose, fructosamine (protein glycation), and insulin levels with hepatic insulin resistance (HOMA-IR) and adipose resistance (IDA-IR) (Table 1). Moreover, hypertriglyceridemia and hypoalphalipoproteinemia (low level of HDL) were observed. These results strongly suggest the development of metabolic syndrome; however, the Long-Evans rats were fed with 5008 diet for one more month to confirm the model. After the second month, the Long-Evans rats showed a 20\% weight gain in comparison to the diet 5001 group (Table 1). Similarly, glucose increased twice as much $(206 \mathrm{mg} / \mathrm{dL})$, fructosamine increased $40 \%$, and insulin increased by $118 \%$, which produced a noticeable insulin resistance level both in the liver and adipose tissue. Dyslipidemia showed a $71 \%$ triglyceride increase and a 15\% HDL decrease (Table 1). These two-month-period results ensure the development of the dysglycemia and dyslipidemia model. Then, rats suffering from metabolic disorder were separated in individual cages, and V10-DMAP dosages of $5 \mu \mathrm{mol}$ and $10 \mu \mathrm{mol}$ (equivalent to $2.43 \mathrm{mg} \cdot \mathrm{V} / \mathrm{kg} /$ day and $4.86 \mathrm{mg} \cdot \mathrm{V} / \mathrm{kg} /$ day, resp.), twice per week, were administered intraperitoneally. Diet consumption was maintained ad libitum.

To justify the fact that the V10-DMAP dose may be used in the treatment of metabolic diseases, both zoometry and biochemical parameters were evaluated in all groups. Overweight was observed in groups which fed a $\mathrm{HC}$ diet (time dependent). Rats starting with an approximate $390 \mathrm{~g}$ weight showed a $36 \mathrm{~g}$ weight gain ( $426 \mathrm{~g} 8$ weeks later). These results mean $5.5 \%$ more weight than the control group (Figure 2(a)). Nonetheless, BMI showed no change, and fat mass percentage showed a significant decrease in the $\mathrm{HC}$ diet group. Remarkably, fat mass increased in the abdominal circumference area, suggesting impaired visceral white adipose tissue, because there was an increase of $8 \%$ in 8 weeks (Figure 2(d)).

Weight was reduced in both groups of rats given with V10-DMAP since the second week was in relation to the NC group. At the end of the V10-DMAP administration, group 3 (5 $\mu \mathrm{mol})$ and group $4(10 \mu \mathrm{mol})$ showed a significant weight reduction of $18 \%$ in relation to the $\mathrm{NC}$ group, while both were $22.5 \%$ lower about the HC group (Figure 2(a)). Likewise, the BMI of groups 3 and 4 improved after two weeks of V10-DMAP administration in $16.5 \%$ and $12 \%$, diminishing up to $24.5 \%$ after eight weeks in comparison to the NC group and $17.5 \%$ in comparison to the HC group (Figure 2(b)). The body fat percentage had a similar pattern. The body fat percentage after two weeks had a similar pattern since the second week in groups 3 and 4 , decreasing $7 \%$ and $6 \%$, respectively. At the end of the experiment ( 8 weeks), the fat percentage was $10 \%$ lower in the NC group and 5\% lower in the HC group (Figure 2(c)). Finally, abdominal perimeter showed a clear reduction. The maximum difference was $11 \%$ after eight weeks in groups 3 and 4 in comparison to the NC group, whereas the difference was $25.5 \%$ in comparison to the HC group for both groups (Figure 2(d)). Similarly, the oral glucose tolerance test showed significant differences in fasting ( $0 \mathrm{~min})$ between the V10-DMAP groups in comparison to the NC group, but at $30 \mathrm{~min}$, the V10-DMAP$10 \mu \mathrm{mol}$ group was also slightly higher. Nevertheless, the area under curve (AUC) analysis showed no difference in both V10DMAP groups. The HC group was evidently different in comparison to the NC group with a $26.5 \%$ increase at $0 \mathrm{~min}$, a $48 \%$ increase at $30 \mathrm{~min}$, a $45.5 \%$ increase at $60 \mathrm{~min}$, a $69 \%$ increase at $90 \mathrm{~min}$, and a $48.5 \%$ at AUC (Figures 3(a) and 3(b)).

Complete biochemical effects are shown in Table 2. In comparison to the NC group, the high-fat diet in the $\mathrm{HC}$ group maintains metabolic dysregulation. Meanwhile, the V10-DMAP administration shows substantial improvements in biochemical parameters. Both groups 3 and 4 regulate their fasting glucose and fructosamine levels, as well as insulin secretion until similar levels are reached as in the NC group. Therefore, hepatic and adipose insulin resistances disappear, and adipokine secretion was almost regulated. In the HC-V10-DMAP-10 $\mu \mathrm{mol}$ group, leptin remained slightly high, whereas adiponectin improved, but it did not recover the level shown by the NC group. In this regard, the HC-V10-DMAP-5 $\mu$ mol group showed an adipokine and a lipid profile return to normal levels, but triglycerides did not diminish like the NC group. Complete lipid regulation was observed in the HC-V10-DMAP-10 $\mu \mathrm{mol}$ group. Notably, HDL level in both groups given with V10-DMAP showed an increase in its concentration, even higher than the NC group. All biochemical parameters in the V10DMAP-administered groups presented an improvement in comparison to the HC group.

On the contrary, biochemical parameters related to hepatic toxicological effects were measured (Table 3). Total bilirubin showed no differences in either group. However, in both the HC group and group 4, the hepatic damage enzymes are increased to $65 \%$ and $26.5 \%$ in AST, increased to $38.5 \%$ in ALT (only in the HC group), $38 \%$ and $27 \%$ in $\gamma$-GT, $27 \%$ and 
TABLE 1: Induction of the dyslipidemia and dysglycemia model.

\begin{tabular}{|c|c|c|c|c|c|}
\hline & \multirow{2}{*}{$\begin{array}{l}15 \text { days fitting-out } \\
5001(n=40)\end{array}$} & \multicolumn{2}{|c|}{1 month } & \multicolumn{2}{|c|}{2 months } \\
\hline & & $5001(n=10)$ & $5008(n=30)$ & $5001(n=10)$ & $5008(n=30)$ \\
\hline Weight (g) & $158 \pm 6.3$ & $230 \pm 7.0$ & $270 \pm 5.0 \Delta$ & $323 \pm 8.7$ & $388 \pm 11.4 \boldsymbol{\Delta}$ \\
\hline Height $(\mathrm{cm})$ & $15.3 \pm 0.6$ & $20.3 \pm 1.7$ & $21.4 \pm 1.4$ & $23.2 \pm 0.8$ & $24.2 \pm 1.1$ \\
\hline Abdominal perimeter $(\mathrm{cm})$ & $13.9 \pm 0.4$ & $15.4 \pm 0.6$ & $16.8 \pm 0.9$ & $17.6 \pm 0.7$ & $18.9 \pm 1.1$ \\
\hline $\mathrm{BMI}\left(\mathrm{g} / \mathrm{cm}^{2}\right)$ & $0.68 \pm 0.07$ & $0.57 \pm 0.08$ & $0.59 \pm 0.08$ & $0.59 \pm 0.03$ & $0.66 \pm 0.04$ \\
\hline \% body fat (Lee index) & $34.7 \pm 0.9$ & $29.8 \pm 2.2$ & $29.8 \pm 1.8$ & $29.2 \pm 0.9$ & $29.6 \pm 1.1$ \\
\hline Glucose $(\mathrm{mg} / \mathrm{dL})$ & $106.0 \pm 4.1$ & $104.9 \pm 4.5$ & $174.3 \pm 3.6 \boldsymbol{\Delta}$ & $104.1 \pm 6.8$ & $206.3 \pm 4.5 \boldsymbol{\Delta}$ \\
\hline Fructosamine $(\mathrm{mmol} / \mathrm{L})$ & $40.8 \pm 0.8$ & $42.8 \pm 1.3$ & $55.3 \pm 2.1 \boldsymbol{\Delta}$ & $43.2 \pm 0.5$ & $60.3 \pm 2.3 \boldsymbol{\Delta}$ \\
\hline Triglycerides (mg/dL) & $58.4 \pm 3.4$ & $75.0 \pm 1.5$ & $104.7 \pm 6.7 \boldsymbol{\Delta}$ & $70.0 \pm 8.2$ & $119.6 \pm 5.5 \boldsymbol{\Delta}$ \\
\hline Total cholesterol (mg/dL) & $86.8 \pm 1.9$ & $75.2 \pm 1.9$ & $72.5 \pm 1.4$ & $78.0 \pm 2.3$ & $80.0 \pm 2.5$ \\
\hline $\mathrm{HDL}(\mathrm{mg} / \mathrm{dL})$ & $45.7 \pm 1.2$ & $49.1 \pm 1.7$ & $41.3 \pm 1.0 \nabla$ & $45.1 \pm 2.0$ & $38.5 \pm 1.0 \nabla$ \\
\hline Insulin $(\mu \mathrm{UI} / \mathrm{mL})$ & $15.3 \pm 0.5$ & $13.3 \pm 0.8$ & $25.9 \pm 2.1 \Delta$ & $15.5 \pm 1.1$ & $33.8 \pm 4.2 \boldsymbol{\Delta}$ \\
\hline HOMA-IR & $0.67 \pm 0.04$ & $0.58 \pm 0.06$ & $1.86 \pm 0.19 \boldsymbol{\Delta}$ & $0.67 \pm 0.09$ & $2.88 \pm 0.42 \boldsymbol{\Delta}$ \\
\hline IDA-IR & $0.11 \pm 0.01$ & $0.18 \pm 0.01$ & $0.4 \pm 0.02 \boldsymbol{\Delta}$ & $0.19 \pm 0.03$ & $0.49 \pm 0.01 \boldsymbol{\Delta}$ \\
\hline
\end{tabular}

Results shown are the average \pm SEM. $\boldsymbol{\Delta}$ indicates a significant difference with values above the control group with a normal calorie diet. $\boldsymbol{\nabla}$ indicates a significant difference with values below the control group with a normal calorie diet. Comparisons between groups were performed by Student's $t$-test. $\mathrm{BMI}=$ body mass index; HDL = high density lipoprotein; HOMA-IR = homeostasis model assessment insulin resistance; IDA-IR = insulin resistance adipocyte dysfunction.

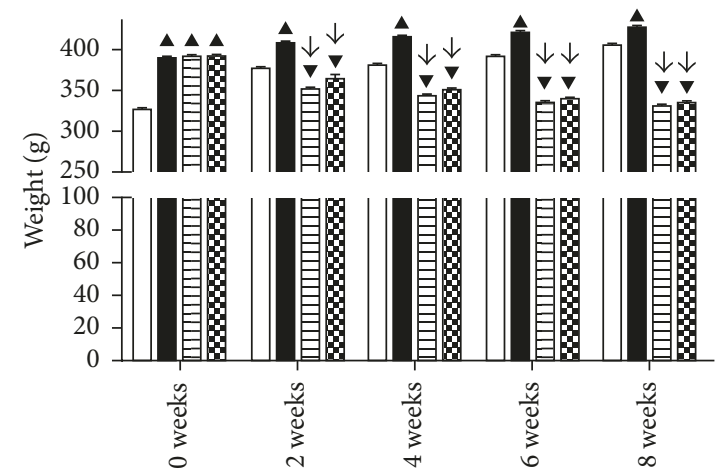

$\square$ NC $\begin{array}{ll}\text { HC } & \text { HC-V10-DMAP-5 } \mu \mathrm{mol} \\ & \end{array}$

(a)

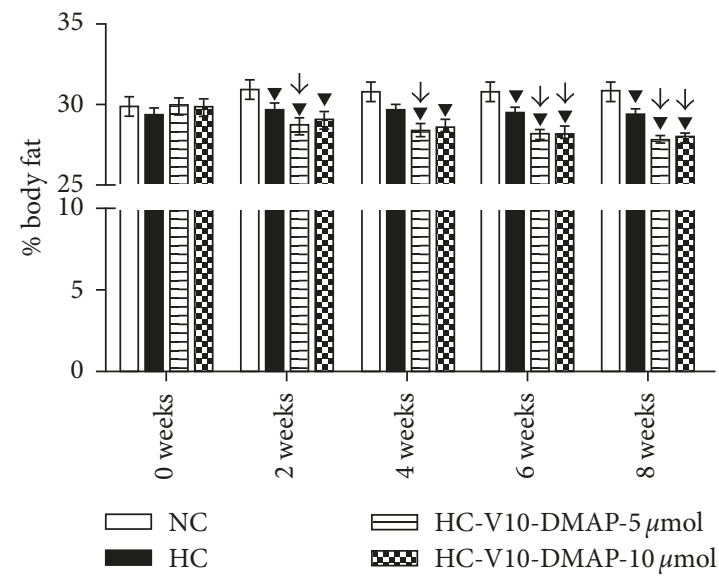

(c)

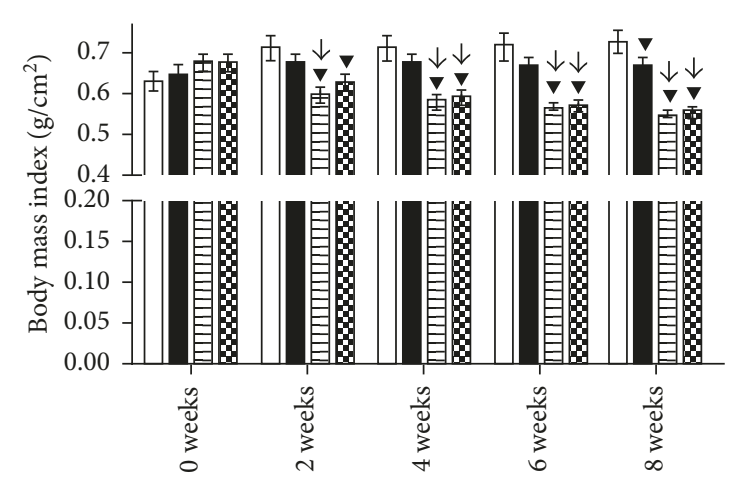

Е HC-V10-DMAP-5 $\mu \mathrm{mol}$

BNo HC-V10-DMAP- $10 \mu \mathrm{mol}$

(b)

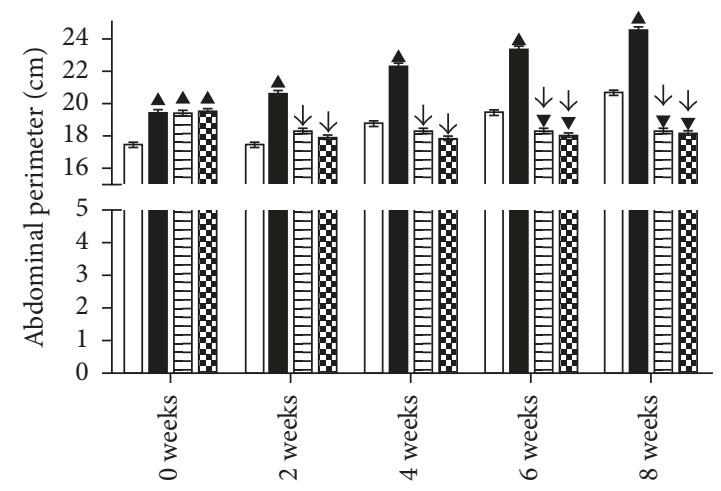

Ð HC-V10-DMAP-5 $\mu \mathrm{mol}$ [No HC-V10-DMAP-10 $\mu \mathrm{mol}$

(d)

Figure 2: Zoometry after diets and V10-DMAP treatments: (a) body weight, (b) BMI, (c) Lee index, the percentage of the body fat mass index, and (d) abdominal perimeter or circumference. Results shown are the average \pm SEM. $\boldsymbol{\Delta}$ indicates a significant difference between values above the control group with a normal calorie diet. $\boldsymbol{\nabla}$ indicates a significant difference between values below the control group with a normal calorie diet. $\downarrow$ indicates a significant difference between values below the HC group. Comparisons between groups were performed by two-way ANOVA and the Bonferroni post hoc test; $p<0.05$. 


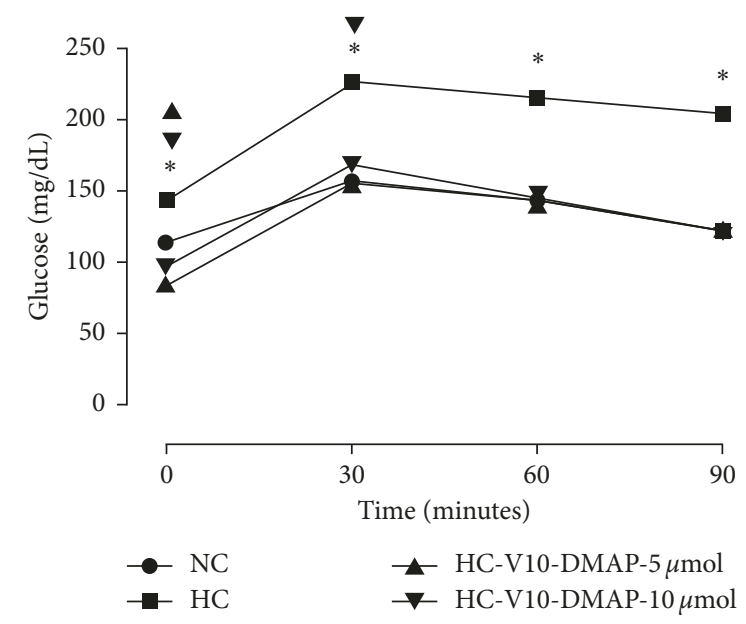

(a)

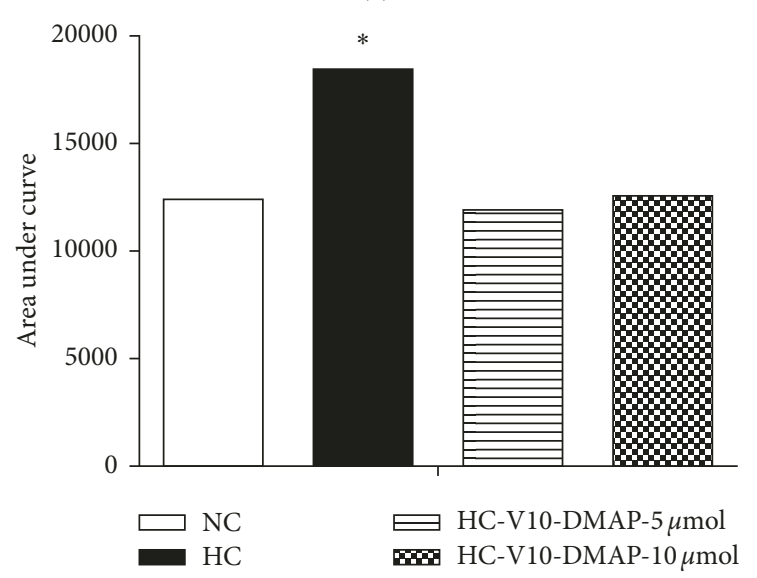

(b)

FIGURE 3: Oral glucose tolerance test and area under the curve after V10-DMAP administration: (a) OGTT $(1.75 \mathrm{~g} / \mathrm{kg}$ weight of anhydrous glucose) ( $n=10$ per group) and (b) graphical representation of AUC analysis. Results shown are the average \pm SEM. * $\boldsymbol{\Delta}$, and $\boldsymbol{\nabla}$ indicate a significant difference among the HC, HC-V10DMAP-5 $\mu \mathrm{M}$, and HC-V10-DMAP-10 $\mu \mathrm{M}$ groups, respectively, in comparison to the $\mathrm{NC}$ group. Comparisons between groups were performed by two-way ANOVA and Bonferroni's post hoc test; $p<0.05$.

$58 \%$ in $\mathrm{LDH}$, respectively. Group 3, which belongs to HCV10-DMAP-5 $\mu \mathrm{mol}$, showed no differences in comparison to the NC group, and all serum biomarkers showed significant differences in comparison to the HC group.

Histological changes were evaluated in tissue sections stained with hematoxylin and eosin ( $\mathrm{H} \& \mathrm{E})$. These changes were viewed under standard bright field illumination. Eosinophilic cytoplasm and blue nuclei, which are characteristic of liver cells, were observed in the liver of the NC group with a distribution of the sinusoid spaces taking the central vein as a reference (Figure 4(a)). The HC group showed visible histology changes, including structure damage, hepatocellular necrosis (black arrow), leukocyte infiltration, recognized as portal inflammation (blue arrow), necrosis, and development of Mallory-Denk bodies, which are an inclusion found in the cytoplasm of hepatocytes. Also, sinusoids between the hepatocyte plates were noticeably enlarged in the liver (Figure 4(b)). Despite that, injuries were of low grade. Liver injury notably diminishes with 5 and $10 \mu \mathrm{mol}$ doses of V10-DMAP, but weak portal inflammation (blue arrow) and slight focal confluent necrosis were observed (Figures $4(\mathrm{c})$ and $4(\mathrm{~d})$ ).

On the contrary, normal histology of adipose tissue is shown in Figure 4(e). Regarding this type of histology, loose connective tissue composed mostly of adipocytes and their storage space (asterisk), and blood vessels can be observed (green arrow). Meanwhile, the HC group showed adipocyte hypertrophy which is characterized by fewer adipocytes (number per analyzed area) with a vascularization increase (Figure 4(f)). Conversely, adipocytes in both groups V10-DMAP reduced their storage area, increasing cell number and vascularization per analyzed area (Figures $4(\mathrm{~g})$ and $4(\mathrm{~h})$ ).

To understand the effects caused by the administration of the V10-DMAP compound, the immunoreactivity in green for the insulin receptor phosphorylated in tyrosine (Tyr 1162/1163) was analyzed in the four study groups. Arbitrary units (pixels) were determined and normalized to the NC group using ImageJ program (data not shown). Regarding the control group, immunoreactivity to hepatic insulin receptor was higher in the HC group (120\%), HC-V10-DMAP-5 $\mu \mathrm{mol}$ group (56\%), and HC-V10-DMAP$10 \mu \mathrm{mol}$ group (81\%) (Figures $5(\mathrm{a})-5(\mathrm{~d})$ ). In visceral white adipose tissue, immunoreactivity in the $\mathrm{HC}$ group was $6 \%$ less than the NC group, while there was a $104 \%$ increase in the HC-V10-DMAP- $5 \mu \mathrm{mol}$ group but only a $20 \%$ increase in the HC-V10-DMAP-10 $\mu \mathrm{mol}$ group (Figures 5(e)-5(h)). Finally, GLUT-4 immunoreactivity in the HC group and HC-V10DMAP- $10 \mu \mathrm{mol}$ group was a $54 \%$ and $28 \%$ less than the NC group, but there was some improvement in comparison to the HC group. Meanwhile, immunoreactivity for GLUT-4 in the HC-V10-DMAP-5 $\mu \mathrm{mol}$ group was higher (33\%) to the NC group (Figures $5(\mathrm{i})-5(\mathrm{l})$ ).

\section{Discussion}

In this paper, we evaluated the metabolic activity of V10DMAP on the dyslipidemia and dysglycemia model. Previously, our working team reported the synthesis and characterization of V10-DMAP by infrared spectroscopy, thermal analysis, and single crystal X-ray diffraction [27]. Similarly, we have previously synthesized and reported another hybrid material based on metformin, a popular drug used to treat type 2 diabetes mellitus [29]. Metformin decavanadate has shown hypoglycemic and hypolipidemic effects on models of type 1 and type 2 diabetes mellitus. Despite vanadium compounds having insulin-mimetic properties, and the first report on their therapeutic properties about diabetes and dyslipidemia appeared in the 20th century $[30,31]$, its mode of action is still poorly understood at the molecular level [30, 32-39]. Although the general population is exposed to vanadium, normal blood concentration rarely exceeds $0.2 \mu \mathrm{M}[3,18,40]$; nonetheless, the therapeutic dose is controversial, because patients have a dependence of vanadium speciation and dose level. 
TABLE 2: Effect of V10-DMAP on biochemical parameters.

\begin{tabular}{|c|c|c|c|c|}
\hline & $\mathrm{NC}(n=10)$ & $\mathrm{HC}(n=10)$ & HC-V10-DMAP-5 $\mu \mathrm{mol}(n=10)$ & HC-V10-DMAP-10 $\mu \mathrm{mol}(n=10)$ \\
\hline Glucose (mg/dL) & $112.5 \pm 3.5$ & $142.3 \pm 6.9 \boldsymbol{\Delta}$ & $84.3 \pm 2.1 \boldsymbol{\nabla} \downarrow$ & $94.8 \pm 5.4 \boldsymbol{\nabla} \downarrow$ \\
\hline Fructosamine $(\mathrm{mmol} / \mathrm{L})$ & $44.6 \pm 0.8$ & $63.8 \pm 1.3 \boldsymbol{\Delta}$ & $45.5 \pm 2.1 \downarrow$ & $38.2 \pm 1.7 \nabla \downarrow$ \\
\hline Triglycerides (mg/dL) & $56.2 \pm 3.4$ & $140.0 \pm 10 \boldsymbol{\Delta}$ & $64.1 \pm 2.8 \boldsymbol{\Delta} \downarrow$ & $60.0 \pm 3.2 \downarrow$ \\
\hline $\mathrm{FFA}(\mathrm{mg} / \mathrm{dL})$ & $2.0 \pm 0.3$ & $7.4 \pm 1.1 \boldsymbol{\Delta}$ & $2.2 \pm 0.1 \downarrow$ & $2.0 \pm 0.1 \downarrow$ \\
\hline Total cholesterol (mg/dL) & $76.9 \pm 4.3$ & $105 \pm 5.1 \boldsymbol{\Delta}$ & $75.2 \pm 3.1 \downarrow$ & $79.0 \pm 4.2 \downarrow$ \\
\hline HDL (mg/dL) & $43.3 \pm 0.9$ & $32.5 \pm 1.1 \nabla$ & $51.1 \pm 1.2 \boldsymbol{\Delta} \uparrow$ & $48.3 \pm 1.5 \boldsymbol{\Delta} \uparrow$ \\
\hline Insulin $(\mu \mathrm{UI} / \mathrm{mL})$ & $17.5 \pm 0.8$ & $63.4 \pm 1.5 \boldsymbol{\Delta}$ & $15.2 \pm 1.5 \downarrow$ & $20.2 \pm 3.1 \downarrow$ \\
\hline Leptin $(\mathrm{ng} / \mathrm{mL})$ & $1.1 \pm 0.02$ & $5.7 \pm 0.2 \boldsymbol{\Delta}$ & $1.2 \pm 0.09 \downarrow$ & $2.1 \pm 0.1 \downarrow$ \\
\hline Adiponectin $(\mu \mathrm{g} / \mathrm{mL})$ & $5.52 \pm 0.3$ & $3.21 \pm 0.2 \nabla$ & $5.12 \pm 0.2 \uparrow$ & $4.32 \pm 0.3 \nabla \uparrow$ \\
\hline HOMA-IR & $0.81 \pm 0.06$ & $3.84 \pm 0.14 \boldsymbol{\Delta}$ & $0.53 \pm 0.06 \nabla \downarrow$ & $0.81 \pm 0.17 \downarrow$ \\
\hline IDA-IR & $0.11 \pm 0.02$ & $0.63 \pm 0.02 \bar{\Delta}$ & $0.09 \pm 0.01 \nabla \downarrow$ & $0.09 \pm 0.01 \nabla \downarrow$ \\
\hline
\end{tabular}

Results shown are the average \pm SEM. $\boldsymbol{\Delta}$ indicates a significant difference with values above the control group with a normal calorie diet. $\boldsymbol{\nabla}$ indicates a significant difference with values below the control group with a normal calorie diet. $\uparrow$ indicates a significant difference with values above the HC group. $\downarrow$ indicates a significant difference with values below the HC group. Comparisons between groups were performed by a two-way ANOVA and the Bonferroni post hoc test; $p<0.05$. FFA = free fatty acids; $\mathrm{HDL}=$ high density lipoprotein; HOMA-IR=homeostasis model assessment insulin resistance; IDA$\mathrm{IR}=$ insulin resistance adipocyte dysfunction.

TABLE 3: Toxicological effect of V10-DMAP administration.

\begin{tabular}{|c|c|c|c|c|}
\hline & $\mathrm{NC}(n=10)$ & $\mathrm{HC}(n=10)$ & HC-V10-DMAP- $5 \mu \mathrm{mol}(n=10)$ & HC-V10-DMAP-10 $\mu \mathrm{mol}(n=10)$ \\
\hline Total bilirubin (mg/dL) & $0.65 \pm 0.03$ & $0.68 \pm 0.02$ & $0.62 \pm 0.03$ & $0.63 \pm 0.04$ \\
\hline AST $(\mathrm{U} / \mathrm{L})$ & $117 \pm 8$ & $193 \pm 11 \boldsymbol{\Delta}$ & $105 \pm 6 \downarrow$ & $148 \pm 7 \boldsymbol{\Delta} \downarrow$ \\
\hline $\operatorname{ALT}(\mathrm{U} / \mathrm{L})$ & $65 \pm 4$ & $90 \pm 7 \boldsymbol{\Delta}$ & $59 \pm 4 \downarrow$ & $78 \pm 4 \downarrow$ \\
\hline$\gamma$-GT $(\mathrm{U} / \mathrm{L})$ & $55 \pm 8$ & $76 \pm 6 \Delta$ & $63 \pm 4 \downarrow$ & $70 \pm 5 \Delta$ \\
\hline $\mathrm{LDH}(\mathrm{U} / \mathrm{L})$ & $200 \pm 12$ & $455 \pm 15 \boldsymbol{\Delta}$ & $220 \pm 14 \downarrow$ & $316 \pm 15 \boldsymbol{\Delta} \downarrow$ \\
\hline
\end{tabular}

Results shown are the average \pm SEM. $\mathbf{\Delta}$ indicates a significant difference with values above the control group with a normal calorie diet. $\downarrow$ indicates a significant difference with values below the HC group. Comparisons between groups were performed by a two-way ANOVA and the Bonferroni post hoc test; $p<0.05 . \mathrm{AST}=$ aspartate aminotransferase; $\mathrm{ALT}=$ alanine aminotransferase; $\gamma$-GT $=$ gamma-glutamyl transpeptidase; $\mathrm{LDH}=$ lactate dehydrogenase .

In this regard, results showed that a micromole dose of decavanadate is sufficient to reach a hypoglycemic effect. Doses of 5 and $10 \mu \mathrm{mol}$ (equivalent to $2.43 \mathrm{mg} \cdot \mathrm{V} / \mathrm{kg} /$ day and $4.86 \mathrm{mg} . \mathrm{V} / \mathrm{kg} /$ day, resp.) showed no difference to discriminate between them. However, when toxicological effects were analyzed, the $10 \mu \mathrm{mol}$ dose had a poor effect on AST, ALT, and LDH activities and did not improve $\gamma$-GT activity in comparison to the $5 \mu \mathrm{mol}$ dose. Toxicological effects of decavanadate, usually in excess, are associated with the production of reactive oxygen species, lipid peroxidation, Fenton reaction increase, and mitochondrial antioxidant enzymes decrease, such as superoxide dismutase (SOD) and catalase activities, which lead to cell death and, releasing transaminases to plasma $[1,2,22,23,41,42]$. Additionally, decavanadate in the range of 1 to $10 \mu \mathrm{mol}$ produced $50 \%$ loss of cell viability in cardiomyocyte cultures [43]. Necrosis is involved in cell death by decavanadate excess, which is shown in Figure 4 where necrosis and inflammation were observed by infiltrating leukocytes, mainly in the V10DMAP- $10 \mu \mathrm{mol}$ group, though there was a reduction of balloon cells or Mallory-Denk bodies and fatty deposits. Meanwhile, the $5 \mu \mathrm{mol}(2.43 \mathrm{mg} \cdot \mathrm{V} / \mathrm{kg} /$ day $)$ dose regulated the enzymatic activities and improved liver histology. In rodents, dosages that normalize glycemia were between 60 and $100 \mathrm{mg} \cdot \mathrm{V} / \mathrm{kg} / \mathrm{day}$, which produced vanadium levels in blood ranging from 10 to $20 \mu \mathrm{M}$. In humans, a dosage of $1.5 \mathrm{mg} \cdot \mathrm{V} / \mathrm{kg} /$ day has reported control of glycemia. On this condition, vanadium in blood is 1 to $5 \mu \mathrm{M}$ [3]. Although in other studies the insulin-mimetic effects of multiple vanadium species (vanadate, peroxovanadates, vanadyl sulfate, etc.) and their powerful hypoglycemic effect have been reported, the $\mathrm{ED}_{50}$ and toxic effects or damage to tissues by vanadium administration have not been shown. Our data suggest that vanadium concentration and the species administered are very important not only for glucose homeostasis but also for the toxicological threshold. Therefore, micromole quantities of decavanadate seem to be a highly druggable polyoxovanadate form.

Thus, it is possible to consider a new prodrug concept that implies dissociation of vanadium complexes before they reach the target biomolecules [44]. In this regard, decavanadate species are usually not considered in vanadium toxicological studies, mainly by speciation of vanadyl $\left(\mathrm{V}^{\mathrm{IV}} \mathrm{O}\right)^{2+}$ or vanadate $\left(\mathrm{V}^{\mathrm{V}} \mathrm{O}_{4}\right)^{3-}$ [45]. It has been proposed that the decomposition rate of decavanadate is slow and can promote either vanadyls or vanadates depending on the cell environment and its requirements, so in the body, its half-life expands hours (few hours in plasma, close to 26 hours in tissues, and after 10 days in urine) [18]. Therefore, the pharmacological activities can be exerted for long periods with a smaller dose that does not reach the toxicological threshold $[46,47]$. During the time that it remains in the body, decavanadate can exert the biological actions.

The Long-Evans rats fed with lipid-rich diet 5008 developed a severe metabolic disorder in lipid and carbohydrates, as well as insulin resistance and hyperleptinemia with hypoadiponectinemia (Table 2 and Figure 3). Additionally, the Long-Evans rats observed overweight and visceral 


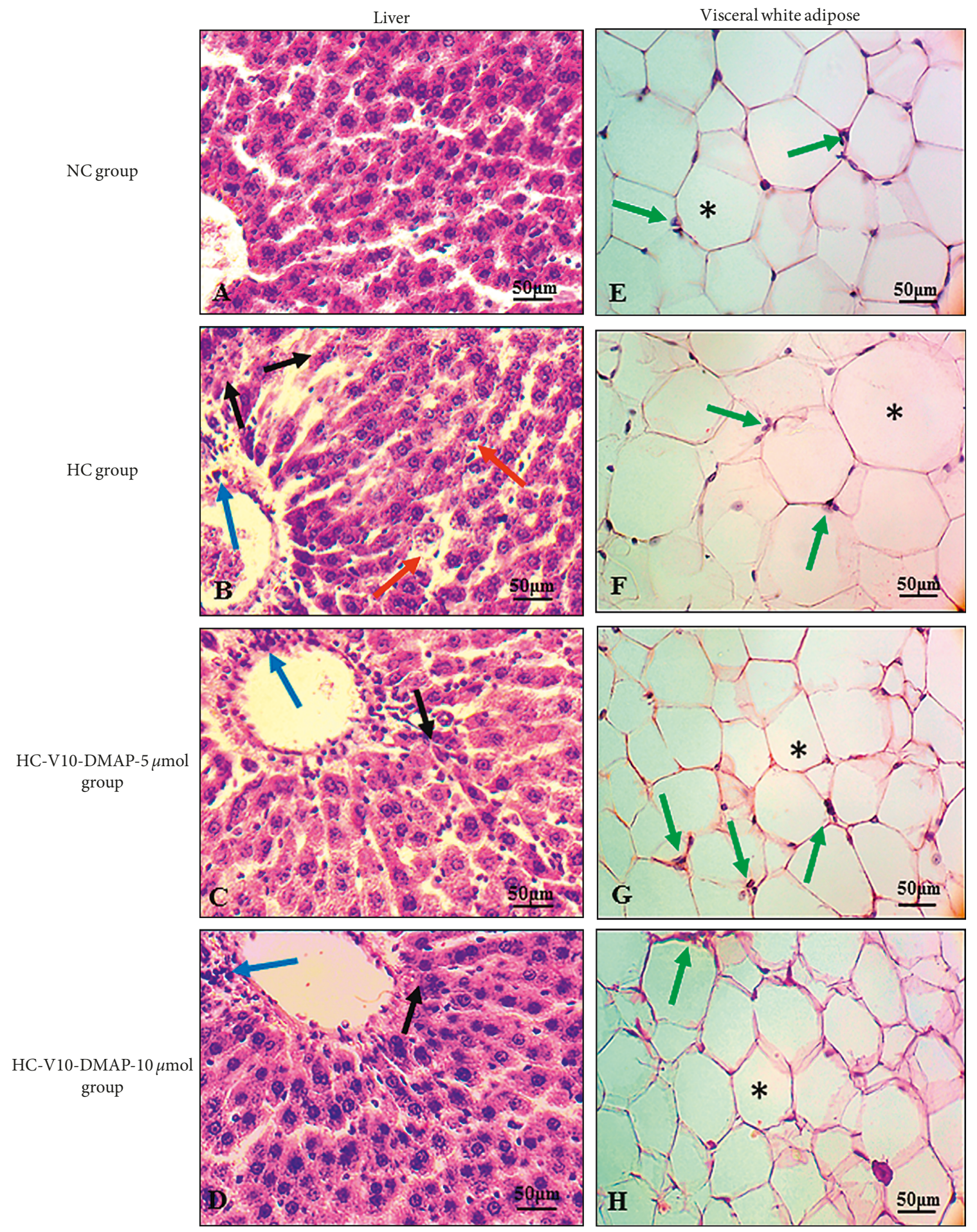

FIGURE 4: Histological features in the liver and visceral white adipose tissue after V10-DMAP administration. (a)-(d) Liver biopsies with H\&E staining. The central vein was taken as a reference. (e)-(h) Visceral adipose tissue biopsies with H\&E staining. Magnification images were acquired with a 40x objective. The blue arrow indicates inflammation by infiltrating leukocytes. The black arrow indicates hepatic cell necrosis. The red arrow indicates balloon cell or Mallory-Denk bodies. The asterisk indicates triglyceride storage area in adipocytes. The green arrow indicates blood vessels.

obesity (Figure 2). In adipocytes, hypertrophy and hyperplasia were evident with an increased area of stored triglycerides and impaired vascularization (Figure 4(f)). Likewise, a decrease in phosphorylation of insulin receptor without GLUT-4 immunoreactivity was observed (Figures 5(f) and 5(j)). Meanwhile, hepatic tissue (Figure 4(b)) showed necrosis, fibrosis, inflammation, fatty droplets, MalloryDenk bodies, and an increase in phosphorylation of insulin 


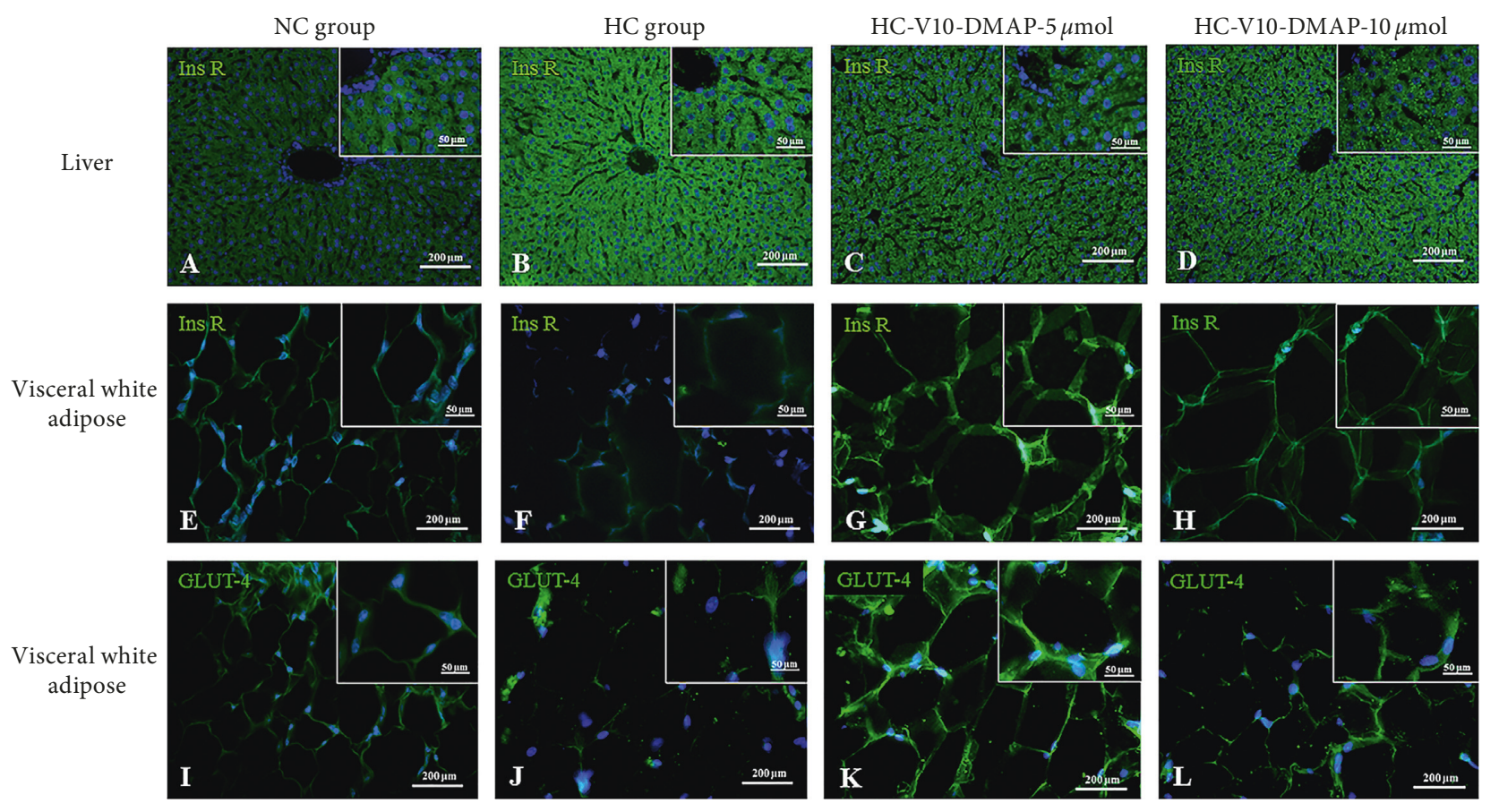

FIgURE 5: Insulin receptor and GLUT-4 in the liver and visceral white adipose tissue after V10-DMAP treatments. Photomicrographs show immunoreactivity to the insulin receptor and GLUT-4, both marked in green and counterstain with DAPI for nuclei, in the liver and adipose tissue. (a)-(d) Hepatic biopsies, insulin receptor phosphorylated in tyrosine (Tyr 1162/1163), and magnification 20x. (e)-(h) Visceral white adipose biopsies, insulin receptor phosphorylated in tyrosine (Tyr 1162/1163), and magnification 40x. (i)-(l) Visceral white adipose biopsies, glucose transporter type 4 insulin-dependent, and magnification 40x.

receptor (Figure 5(b)). These results are completely associated with insulin resistance, dyslipidemia, and metabolic syndrome. Some studies based on hyperinsulinemic-euglycemic clamp experiments have consistently demonstrated a wholebody insulin resistance in animal fat-fed rodents [48], thus matching with the biochemical parameters and the excess caloric intake reported herein. Insulin resistance is usually accompanied by hyperinsulinemia that promotes an ectopic lipid accumulation and a glucose transport decrease $[49,50]$. Ectopic lipid accumulation is recognized as steatosis that leads to lipotoxicity and is strongly linked to insulin resistance, metabolic syndrome, and diabetes mellitus development $[51,52]$.

Particularly, fat mass accumulation during obesity development is characterized by adipocyte hyperplasia and hypertrophy, which increases the production of proinflammatory adipokines that lead to a state of chronic lowgrade inflammation and may promote obesity linked to metabolic disorders, such as insulin resistance and metabolic syndrome [7]. Inflammation may impair insulin action systemically by increasing free fatty acids (FFA) or proinflammatory adipokines, such as leptin, which is a key hormone involved in the regulation of satiety, energy intake, and energy expenditure. Thus, hyperleptinemia does not suppress appetite, a phenomenon known as leptin resistance [53-57]. Leptin resistance is thought to be a fundamental pathology in nonalcoholic fatty liver development, insulin resistance, glucose tolerance impairment, and dyslipidemia as was observed in rats fed with diet 5008. On the contrary, adiponectin regulates lipid and glucose metabolism and increases insulin sensitivity, regulates food intake and body weight, and protects against chronic inflammation. It also increases glucose transport in muscles and enhances fatty acid oxidation, so it is considered anti-inflammatory, antiatherogenic, anti-insulin resistance, and antimetabolic syndrome adipokine [7, 58-62]. Metabolically dysregulated rats showed severe hypoadiponectinemia and consequently insulin resistance in liver and adipose tissue. Insulin resistance implies changes upon insulin signaling, mainly in a transphosphorylation reaction that activates the insulin receptor substrate (IRS), an intrinsic kinase that activates the phosphatidylinositol 3-kinase- (PI3K-) AKT/protein kinase $\mathrm{B}$ (PKB) pathway to modulate most metabolic functions of insulin, such as glucose transport by GLUT-4 in adipocytes and myocytes. Meanwhile, this pathway modulates glycogen synthesis, gluconeogenesis, and protein synthesis in liver [63]. On the contrary, it also signals cell growth by the Ras-mitogenactivated protein kinase (MAPK) pathway [63-65]. Inflammatory adipokines enhance degradation of IRS1/2 by the protein tyrosine phosphatase 1B (PTP1B) activity. Therefore, GLUT-4 protein diminished in adipocytes, impairing glucose tolerance response in return to basal levels after a glucose load. In addition, it promoted triglyceride synthesis in the liver associated with insulin receptor hyperphosphorylation, as observed in rats which were fed a high-lipid diet.

It is remarkable that, since its early discovery, the insulin-like activity of vanadium has been considered to be an insulin-mimetic agent that reaches glucose regulation by similar pathways to the hormone. However, the metabolic model, where the defect is caused by hyperinsulinemia and 
insulin resistance, has not considered that the hormone is at high levels. Therefore, if vanadium has only affected, such as an insulin-mimetic agent, the defect would be promoted. In this respect, vanadium has proven to be a powerful inhibitor of protein tyrosine phosphatases (PTPs), improving tyrosine phosphorylation of IRS1/2 in rat adipocytes and cardiomyocytes, which lead to activation of its associated PI3K activity $[66,67]$ and PKB [68-70], stimulation of glucose uptake [71, 72], and GLUT4 translocation $[73,74]$. Also, vanadium in liver enhances phosphorylation of ERK1/2, PKB, and glycogen synthase kinase- (GSK-) $3 \beta[71,75]$. As a result, vanadium acts efficiently on insulin phosphorylation cascade, probably because of its structural analogy between vanadate and phosphate, where the monomeric vanadate is slightly larger than the phosphate [18]. Moreover, several studies suggest that vanadium is involved in the regulation of phosphatedependent processes, such as metabolic processes involving phosphatases and kinases. However, the toxicological threshold of vanadium compounds must always be taken into consideration because more metal into cells may cause damage or simply a loss of efficiency. As it can be seen, the V10-DMAP-10 $\mu \mathrm{mol}$ group does not reach the insulin receptor phosphorylation levels in both adipose tissue and liver compared with the V10-DMAP-5 $\mu$ mol group, where even GLUT-4 protein is regulated more efficiently.

Although the vanadium mechanism on metabolic regulation has been described, decavanadate as an insulinmimetic agent or enhancer is not fully understood, but its insulin-mimetic effects are probably related to the inhibition of tyrosine phosphatase-1B (PTP1B) [45]. Recently, it has been reported that the signal transduction pathway of PTP1B is influenced by reactive oxygen species (ROS) generated into metabolic cascades [44], so vanadium may be able to act as insulin mimetics due to changes in prooxidant and oxidant balance. In this respect, decavanadate has been observed to inhibit mitochondrial respiration of hepatocytes with 100-fold more power than vanadate, diminishing oxygen consumption and ROS production, which is related to mitochondrial complex III [43]. Inhibition of mitochondrial complexes make cells require more energy, so the burning of lipids and carbohydrates and the FFA flux from adipocytes to hepatocytes are continuously maintained for the adipose tissue to return to a morphology similar to the control group. Thus, the adiponectin level was regulated (decreasing leptin and increasing adiponectin). Meanwhile, decreased fatty content and glucose balance in the liver are improved, so glucose tolerance is also improved, and there are less fructosamine formation and insulin need, leading to insulin resistance reduction, both in adipocytes and hepatic tissue. Therefore, hepatocytes showed an injury reduction. Notably, the $5 \mu \mathrm{mol}$ (equivalent to $2.43 \mathrm{mg} \cdot \mathrm{V} / \mathrm{kg} /$ day) dose was more efficient than the $10 \mu \mathrm{mol}(4.86 \mathrm{mg} \cdot \mathrm{V} / \mathrm{kg} /$ day $)$ dose. Supporting these facts, in previous studies, our working team has demonstrated that metforminium decavanadate produces metabolic regulation on carbohydrates and lipids in hyperinsulinemia and hypoinsulinemia models [76-79], regardless of the insulin-mimetic action by vanadium.

\section{Conclusion}

The V10-DMAP administration, only twice per week, produced regulation on lipids and carbohydrates, regardless of dose administered here; yet, the V10-DMAP-5 $\mu \mathrm{mol}$ $(2.43 \mathrm{mg} \cdot \mathrm{V} / \mathrm{kg} /$ day) dose showed more effective effects than the V10-DMAP- $10 \mu \mathrm{mol}(4.86 \mathrm{mg} \cdot \mathrm{V} / \mathrm{kg} /$ day $)$ dose in the liver, which was confirmed by enzymatic activity. In adipose tissue, the V10-DMAP-5 $\mu \mathrm{mol}(2.43 \mathrm{mg} \cdot \mathrm{V} / \mathrm{kg} /$ day) dose was also more beneficial on cells and adipokines. In this regard, a low decavanadate dose produced a clear regulation of the insulin signaling pathway. Furthermore, different experiments strongly suggest that vanadium and its species in the cell may act on proteins, such as phosphorylases and kinases, so it should not be considered only as an insulin-mimetic agent, and a deeper understanding of its mechanism of action needs to be further investigated. The pharmacological and toxicological threshold for cell regulation are suggested to be up to $5 \mu \mathrm{mol}(2.43 \mathrm{mg} \cdot \mathrm{V} / \mathrm{kg} /$ day $)$ for the title compound.

\section{Data Availability}

The data that support the findings of this study are available from the corresponding author upon reasonable request.

\section{Conflicts of Interest}

The authors declare that they do not have conflicts of interest.

\section{Acknowledgments}

The authors wish to thank Vicerrectoria de Investigación y Estudios de Posgrado (VIEP) by Dr. Ygnacio Martínez Laguna and the Dirección de Innovación y Transferencia de Conocimiento (DITCO) through Dr. Pedro Hugo Hernández Tejeda and Dr. Martín Pérez Santos from Oficina de Comercialización de Tecnología (OCT) for financial support to carry out this research project (DITCO2016-8). The authors also thank Dr. Carlos Escamilla for the use of the Vivarium "Claude Bernard" and Yadira Rosas Bravo for technical assistance. E. Sánchez-Lara wishes to thank Consejo Nacional de Ciencia y Tecnología (CONACyT) for the PhD fellowship support granted with number 293256.

\section{Supplementary Materials}

Supplementary 1. Figure S6: kidney histology after V10DMAP administration.

Supplementary 2. Table S4: renal function after V10-DMAP administration.

\section{References}

[1] D. Rehder, "The potentiality of vanadium in medicinal applications," Future Medicinal Chemistry, vol. 4, no. 14, pp. 1823-1837, 2012.

[2] D. Rehder, "The future of/for vanadium," Dalton Transactions, vol. 42, no. 33, p. 11749, 2013. 
[3] A. Goc, "The biological activity of vanadium compounds," Central European Journal of Biology, vol. 1, no. 3, pp. 314-332, 2003.

[4] F. H. Nielsen and E. O. Uthus, "Essentiality and metabolism of vanadium," in Vanadium in Biological Systems, N. D. Chasteen, Ed., pp. 51-62, Kluwer Academic Publishers, Dordrecht, The Netherlands, 1990.

[5] R. J. French and P. J. H. Jones, "The role of vanadium in nutrition: metabolism, essentiality and dietary considerations," Life Sciences, vol. 52, no. 4, pp. 339-346, 1993.

[6] B. Mukherjee, B. Patra, S. Mahapatra, P. Banerjee, A. Tiwari, and M. Chatterjee, "Vanadium-an element of biological significance," Toxicology Letters, vol. 150, no. 2, pp. 135-143, 2004.

[7] J. Kaur, "A comprehensive review on metabolic syndrome," Cardiology Research and Practice, vol. 2014, Article ID 943162, 21 pages, 2014.

[8] S. Desroches and B. Lamarche, "Evolving definitions and increasing prevalence of metabolic syndrome," Applied Physiology: Nutrition and Metabolism, vol. 32, no. 1, pp. 2332, 2007.

[9] G. D. Kolovou, K. K. Anagnostopoulou, K. D. Salpea, and D. P. Mikhailidis, "The prevalence of metabolic syndrome in various populations," American Journal of the Medical Sciences, vol. 333, no. 6, pp. 362-371, 2007.

[10] A. J. Cameron, J. E. Shaw, and P. Z. Zimmet, "Metabolic syndrome: prevalence in worldwide populations," Endocrinology and Metabolism Clinics of North America, vol. 33, no. 2, pp. 351-375, 2004.

[11] A. Nourparvar, A. Bullota, U. Di Mario, and R. Perfetti, "Novel strategies for the pharmacological management of type II diabetes," Trends in Pharmacological Sciences, vol. 25, no. 2, pp. 86-91, 2004.

[12] K. H. Thompson and C. Orvig, "Vanadium compounds in the treatment of diabetes," Metal Ions in Biological Systems, vol. 41, pp. 221-225, 2004.

[13] H. Sakurai, "Therapeutic potential of vanadium in treating diabetes mellitus," Clinical Calcium, vol. 15, pp. 49-57, 2005.

[14] X. G. Yang, K. Wang, J. Lu, and D. C. Crans, "Membrane transport of vanadium compounds and interaction with the erythrocyte membrane," Coordination Chemistry Reviews, vol. 273, no. 1-2, pp. 103-111, 2003.

[15] D. C. Crans, R. L. Bunch, and L. A. Theisen, "Interaction of trace levels of vanadium (IV) and vanadium (V) in biological systems," Journal of the American Chemical Society, vol. 111, no. 19, pp. 7597-7607, 1989.

[16] D. C. Crans, "Antidiabetic, chemical and physical properties of organic vanadate as presumed transition state inhibitors for phosphatases," Journal of Organic Chemistry, vol. 80, no. 24, pp. 11899-11915, 2015.

[17] D. C. Crans, "Fifteen years of dancing with vanadium," Pure and Applied Chemistry, vol. 77, no. 9, pp. 1497-1527, 2005.

[18] J. C. Pessoa, S. Etcheverry, and D. Gambino, "Vanadium compounds in medicine," Coordination Chemistry Reviews, vol. 301-302, pp. 24-48, 2015.

[19] D. C. Crans, "Vanadium and its role in life," in Metal Ions in Biological Systems, A. Sigel and H. Sigel, Eds., pp. 147-209, Marcel Dekker, New York, NY, USA, 1995.

[20] M. Aureliano, "Decavanadate: a journey in search of a role," Dalton Transactions, no. 42, pp. 9093-9100, 2009.

[21] M. Aureliano and D. C. Crans, "Decavanadate $\mathrm{V}_{10} \mathrm{O}_{28}{ }^{6-}$ and oxovanadates: oxometalates with many biological activities," Journal of Inorganic Biochemistry, vol. 103, no. 4, pp. 536-546, 2009.
[22] J. L. Domingo, "Vanadium and tungsten derivatives as antidiabetic agents: a review of their toxic effects," Biological Trace Element Research, vol. 88, no. 2, pp. 97-112, 2002.

[23] J. L. Domingo, M. Gomez, D. J. Sanchez, J. M. Llobet, and C. L. Keen, "Toxicology of vanadium compounds in diabetic rats: action of chelating agents on vanadium accumulation," Molecular and Cellular Biochemistry, vol. 153, no. 1-2, pp. 233-240, 1995.

[24] M. C. Cam, R. A. Pederson, R. W. Brownsey, and J. H. McNeill, "Long-term effectiveness of vanadyl sulfate in streptozotocin-diabetic rats," Diabetologia, vol. 36, no. 3, pp. 218-224, 1993.

[25] T. Scior, J. A. Guevara-Garcia, P. Bernard, D. Quoc-Tuan, D. Domeyer, and S. Laufer, "Are vanadium compounds drugable? Structures and effects of antidiabetic vanadium compounds: a critical review," Mini-Reviews in Medicinal Chemistry, vol. 5, no. 11, pp. 995-1008, 2005.

[26] M. Aureliano and R. M. C. Gándara, "Decavanadate effects on biological systems," Journal of Inorganic Biochemistry, vol. 99, no. 5, pp. 979-985, 2005.

[27] E. Sánchez-Lara, I. Sánchez-Lombardo, A. Pérez-Benítez, A. Mendoza, M. Flores-Álamo, and E. González-Vergara, “A new dicationic ring $\left[(\text { water })_{6}-(\text { ammonium })_{2}\right]$ acts as a building block for a supramolecular 3D assembly of decavanadate clusters and 4-( $N, N$-dimethylamino)pyridinium ions," Journal of Cluster Science, vol. 26, no. 3, pp. 901-912, 2014.

[28] S. Treviño, M. P. Waalkes, J. A. Flores Hernández, B. A. LeónChávez, P. Aguilar-Alonso, and E. Brambila, "Chronic cadmium exposure in rats produces pancreatic impairment and insulin resistance in multiple peripheral tissues," Archives of Biochemistry and Biophysics, vol. 583, pp. 27-35, 2015.

[29] I. Sánchez-Lombardo, E. Sánchez-Lara, A. Pérez-Benítez, A. Mendoza, S. Bernès, and E. González-Vergara, "Synthesis of metforminium $(2+)$ decavanadates-crystal structures and solid-state characterization," European Journal of Inorganic Chemistry, vol. 2014, no. 27, pp. 4581-4588, 2014.

[30] J. Korbecki, I. Baranowska-Bosiacka, I. Gutowska, and D. Chlubek, "Biochemical and medical importance of vanadium compounds," Acta Biochimica Polonica (ABP), vol. 59, no. 2, pp. 195-200, 2012.

[31] H. Sakurai, "A new concept: the use of vanadium complexes in the treatment of diabetes mellitus," The Chemical Record, vol. 2, no. 4, pp. 237-248, 2002.

[32] C. E. Heyliger, A. G. Tahiliani, and J. H. McNeill, "Effect of vanadate on elevated blood glucose and depressed cardiac performance of diabetic rats," Science, vol. 227, no. 4693, pp. 1474-1477, 1985.

[33] J. Meyerovitch, Z. Farfel, J. Sack, and Y. Shechter, "Oral administration of vanadate normalizes blood glucose levels in streptozotocin-treated rats. Characterization and mode of action," Journal of Biological Chemistry, vol. 262, pp. 66586662, 1987.

[34] M. Bendayan and D. Gingras, "Effect of vanadate administration on blood glucose and insulin levels as well as on the exocrine pancreatic function in streptozotocin-diabetic rats," Diabetologia, vol. 32, no. 8, pp. 561-567, 1989.

[35] S. M. Brichard, "Effects of vanadate on the expression of genes involved in fuel homeostasis in animal models of type I and type II diabetes," Molecular and Cellular Biochemistry, vol. 153, no. 1-2, pp. 121-124, 1995.

[36] S. M. Brichard, W. Okitolonda, and J. C. Henquin, "Longterm improvement of glucose homeostasis by vanadate treatment in diabetic rats," Endocrinology, vol. 123, no. 4, pp. 2048-2053, 1988. 
[37] S. M. Brichard, J. Lederer, and J. C. Henquin, "Insulin-like properties of vanadium: a curiosity or a perspective for the treatment of diabetes?" Diabetes \& Metabolism, vol. 17, pp. 435-440, 1991.

[38] R. A. Pederson, S. Ramanadham, A. M. Buchan, and J. H. McNeill, "Long-term effects of vanadyl treatment on streptozocin-induced diabetes in rats," Diabetes, vol. 38, no. 11 , pp. 1390-1395, 1989.

[39] S. Ramanadham, J. J. Mongold, R. W. Brownsey, G. H. Cros, and J. H. McNeill, "Oral vanadyl sulfate in the treatment of diabetes mellitus in rats," American Journal of PhysiologyHeart and Circulatory Physiology, vol. 257, no. 3, pp. H904H911, 1989.

[40] Agency for Toxic Substance and Disease Registry (ATSDR), U.S. Toxicological Profile for Vanadium, Department of Healthand Human Services, Public Health Service, Centers for Disease Control, Atlanta, GA, USA, 2012, http://www. atsdr.cdc.gov/toxprofiles/tp58.pdf.

[41] M. Aureliano and C. A. Ohlin, "Decavanadate in vitro and in vivo effects: facts and opinions," Journal of Inorganic Biochemistry, vol. 137, pp. 123-130, 2014.

[42] J. Z. Byczkowski and A. P. Kulkarni, "Oxidative stress and prooxidant biological effects of vanadium," in Vanadium in the Environment, Part 1: Chemistry and Biochemistry, J. O. Nriagu, Ed., pp. 235-263, John Wiley \& Sons, New York, NY, USA, 1998.

[43] S. S. Soares, F. Henao, M. Aureliano, and C. Gutierrez-Merino, "Vanadate induces necrotic death in neonatal rat cardiomyocytes through mitochondrial membrane depolarization," Chemical Research in Toxicology, vol. 21, no. 3, pp. 607-618, 2008.

[44] T. Scior, J. A. Guevara-García, Q. T. Do, P. Bernard, and S. Laufer, "Why antidiabetic vanadium complexes are not in the pipeline of "Big Pharma" drug research? A critical review," Current Medicinal Chemistry, vol. 23, no. 25, pp. 2874-2891, 2016.

[45] M. Aureliano, "Decavanadate toxicology and pharmacological activities: V10 or V1, both or none?," Oxidative Medicine and Cellular Longevity, vol. 2016, Article ID 6103457, 8 pages, 2016.

[46] G. Borges, P. Mendonça, N. Joaquim, J. Coucelo, and M. Aureliano, "Acute effects of vanadate oligomers on heart, kidney and liver histology in the Lusitanian toadfish ( $\mathrm{Hal}$ obatrachus didactylous)," Archives of Environmental Contamination and Toxicology, vol. 45, no. 3, pp. 415-422, 2003.

[47] S. Ramos, M. Manuel, T. Tiago et al., "Decavanadate interactions with actin: inhibition of G-actin polymerization and stabilization of decameric vanadate," Journal of Inorganic Biochemistry, vol. 100, no. 11, pp. 1734-1743, 2006.

[48] R. Buettner, J. Schölmerich, and L. C. Bollheimer, "High-fat diets: modeling the metabolic disorders of human obesity in rodents," Obesity, vol. 15, no. 4, pp. 798-808, 2007.

[49] G. Boden and F. Jadali, "Effects of lipid on basal carbohydrate metabolism in normal men," Diabetes, vol. 40, no. 6, pp. 686-692, 1991.

[50] G. Boden and X. Chen, "Effects of fat on glucose uptake and utilization in patients with non-insulin-dependent diabetes," Journal of Clinical Investigation, vol. 96, no. 3, pp. 1261-1268, 1995.

[51] A. Mitrakou, D. Kelley, M. Mokan et al., "The role of reduced suppression of glucose production and diminished early insulin release in impaired glucose tolerance," New England Journal of Medicine, vol. 326, no. 1, pp. 22-29, 1992.

[52] L. Rossetti, A. Giaccari, N. Barzilai, K. Howard, G. Sebel, and $\mathrm{M}$. $\mathrm{Hu}$, "The mechanism by which hyperglycemia inhibits hepatic glucose production in conscious rats: implications for the pathophysiology of fasting hyperglycemia in diabetes," Journal of Clinical Investigation, vol. 92, no. 3, pp. 1126-1134, 1993.

[53] J. A. Kim, M. Montagnani, K. K. Koh, and M. J. Quon, "Reciprocal relationships between insulin resistance and endothelial dysfunction: molecular and pathophysiological mechanisms," Circulation, vol. 113, no. 15, pp. 1888-1904, 2006.

[54] K. Makki, P. Froguel, and I. Wolowczuk, "Adipose tissue in obesity-related inflammation and insulin resistance: cells, cytokines, and chemokines," ISRN Inflammation, vol. 2013, Article ID 139239, 12 pages, 2013.

[55] I. Szanto and C. R. Kahn, "Selective interaction between leptin and insulin signaling pathways in a hepatic cell line," Proceedings of the National Academy of Sciences, vol. 97, no. 5, pp. 2355-2360, 2000.

[56] P. Z. Zimmet, V. R. Collins, M. P. de Courten et al., "Is there a relationship between leptin and insulin sensitivity independent of obesity? A population-based study in the Indian Ocean nation of Mauritius," International Journal of Obesity, vol. 22, no. 2, pp. 171-177, 1998.

[57] J. J. T. Liaw and P. V. Peplow, "Differential effect of electroacupuncture on inflammatory adipokines in two rat models of obesity," Journal of Acupuncture and Meridian Studies, vol. 9, no. 4, pp. 183-190, 2016.

[58] Y. Sharabi, M. Oron-Herman, Y. Kamari et al., "Effect of PPAR-gamma agonist on adiponectin levels in the metabolic syndrome: lessons from the high fructose fed rat model," American Journal of Hypertension, vol. 20, no. 2, pp. 206-210, 2007.

[59] Y. Matsuzawa, T. Funahashi, S. Kihara, and I. Shimomura, "Adiponectin and metabolic syndrome," Arteriosclerosis, Thrombosis, and Vascular Biology, vol. 24, no. 1, pp. 29-33, 2004.

[60] T. Kazumi, A. Kawaguchi, K. Sakai, T. Hirano, and G. Yoshino, "Young men with high-normal blood pressure have lower serum adiponectin, smaller LDL size and higher elevated heart rate than those with optimal blood pressure," Diabetes Care, vol. 25, no. 6, pp. 971-976, 2002.

[61] T. Pischon, C. J. Girman, G. S. Hotamisligil, N. Rifai, F. B. Hu, and E. B. Rimm, "Plasma adiponectin levels and risk of myocardial infarction in men," Journal of the American Medical Association, vol. 291, no. 14, pp. 1730-1737, 2004.

[62] L. Hutley and J. B. Prins, "Fat as an endocrine organ: relationship to the metabolic syndrome," American Journal of the Medical Sciences, vol. 330, no. 6, pp. 280-289, 2005.

[63] H. Kwon and J. E. Pessin, "Adipokines mediate inflammation and insulin resistance," Frontiers in Endocrinology, vol. 4, no. 71, pp. 1-13, 2013.

[64] S. Boura-Halfon and Y. Zick, "Phosphorylation of IRS proteins, insulin action, and insulin resistance," American Journal of Physiology-Endocrinology and Metabolism, vol. 296, no. 4, pp. E581-E591, 2009.

[65] L. Fontana, J. C. Eagon, M. E. Trujillo, P. E. Scherer, and S. Klein, "Visceral fat adipokine secretion is associated with systemic inflammation in obese humans," Diabetes, vol. 56, no. 4, pp. 1010-1013, 2007.

[66] S. K. Pandey, M. B. Anand-Srivastava, and A. K. Srivastava, "Vanadyl sulfate-stimulated glycogen synthesis is associated with activation of phosphatidylinositol 3 kinase and is independent of insulin receptor tyrosine phosphorylation," Biochemistry, vol. 37, no. 19, pp. 7006-7014, 1998.

[67] G. Elberg, Z. He, J. Li, N. Sekar, and Y. Shechter, "Vanadate activates membranous non-receptor protein tyrosine kinase 
in rat adipocytes," Diabetes, vol. 46, no. 11, pp. 1684-1690, 1997.

[68] A. Mohammad, S. Bhanot, and J. H. McNeill, "In vivo effects of vanadium in diabetic rats are independent of changes in PI3 kinase activity in skeletal muscle," Molecular and Cellular Biochemistry, vol. 223, no. 1-2, pp. 103-108, 2001.

[69] L. Marzban, S. Bhanot, and J. H. McNeill, "In vivo effects of insulin and bis(maltolato)oxovanadium (IV) on PKB activity in the skeletal muscle and liver of diabetic rats," Molecular and Cellular Biochemistry, vol. 223, no. 1-2, pp. 147-157, 2001.

[70] S. Semiz and J. H. McNeill, "Oral treatment with vanadium of Zucker fatty rats activates muscle glycogen synthesis and insulin-stimulated protein phosphatase-1 activity," Molecular and Cellular Biochemistry, vol. 236, no. 1-2, pp. 123-131, 2002.

[71] B. I. Posner, R. Faure, J. W. Burgess et al., "Peroxovanadium compounds: a new class of potent phosphotyrosine phosphatase inhibitors which are insulin mimetics," Journal of Biological Chemistry, vol. 269, pp. 4596-4604, 1994.

[72] J. Berger, N. Hayes, D. M. Szalkowski, and B. Zhang, "PI-3 kinase activation is required for insulin stimulation of glucose transport into L6 myotubes," Biochemical and Biophysical Research Communications, vol. 205, no. 1, pp. 570-576, 1994.

[73] R. V. Donthi, B. Huisamen, and A. Lochner, "Effect of vanadate and insulin on glucose transport in isolated adult rat cardiomyocytes," Cardiovascular Drugs and Therapy, vol. 14, no. 5, pp. 463-470, 2000.

[74] J. Li, G. Elberg, N. Sekar, H. Z. Bin, and Y. Shechter, "Antilipolytic actions of vanadate and insulin in rat adipocytes mediated by distinctly different mechanisms," Endocrinology, vol. 138, no. 6, pp. 2274-2279, 1997.

[75] G. Swarup, S. Cohen, and D. L. Garbers, "Inhibition of membrane phosphotyrosyl-protein phosphatase activity by vanadate," Biochemical and Biophysical Research Communications, vol. 107, no. 3, pp. 1104-1109, 1982.

[76] A. J. Davison, Q. Wu, J. Moon, and A. Stern, “Among a range of transition metals and ligands, vanadium desferroxamine excels in accelerating reactivity of ferrocytochrome $\mathrm{C}$ toward molecular oxygen," Biochemistry and Cell Biology, vol. 72, no. 5-6, pp. 169-174, 1994.

[77] M. J. Hosseini, F. Shaki, M. Ghazi-Khansari, and J. Pourahmad, "Toxicity of vanadium on isolated rat liver mitochondria: a new mechanistic approach," Metallomics, vol. 5, no. 2, pp. 152-166, 2013.

[78] S. Treviño, D. Velázquez-Vázquez, E. Sánchez-Lara et al., "Metforminium decavanadate as a potential metallopharmaceutical drug for the treatment of diabetes mellitus," Oxidative Medicine and Cellular Longevity, vol. 2016, Article ID 6058705, 14 pages, 2016.

[79] S. Treviño, E. Sánchez-Lara, V. E. Sarmiento-Ortega et al., "Hypoglycemic, lipid-lowering and metabolic regulation activities of metforminium decavanadate $\left(\mathrm{H}_{2} \mathrm{Metf}\right)_{3}\left[\mathrm{~V}_{10} \mathrm{O}_{28}\right]$. $8 \mathrm{H}_{2} \mathrm{O}$ using hypercaloric-induced carbohydrate and lipid deregulation in Wistar rats as biological model," Journal of Inorganic Biochemistry, vol. 147, pp. 85-92, 2015. 

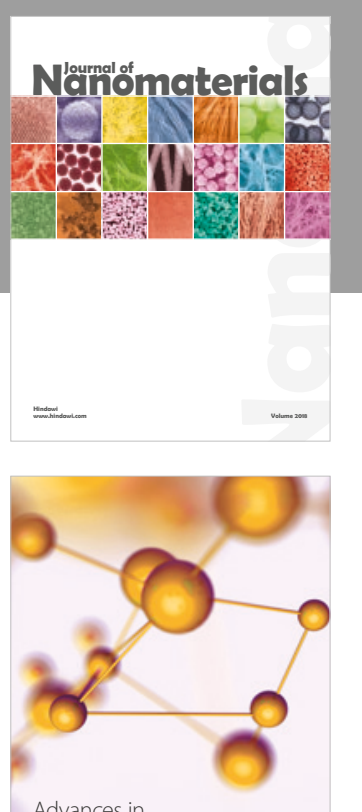

Physical Chemistry
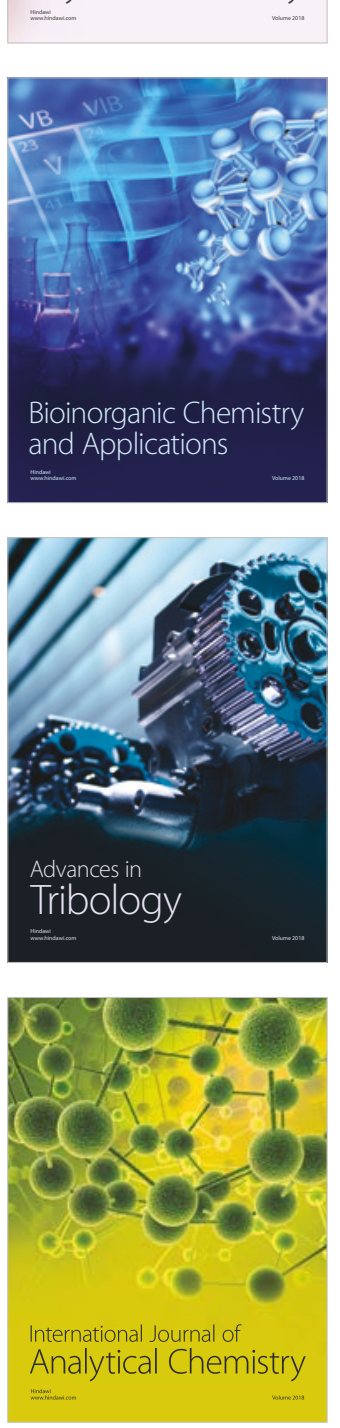

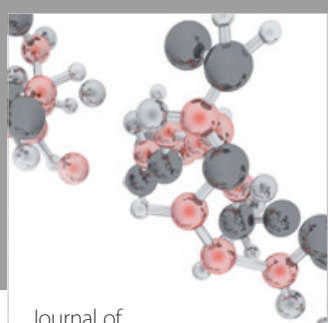

Analytical Methods

in Chemistry

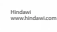

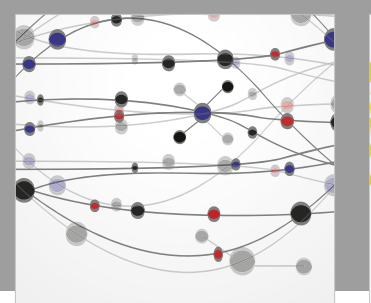

The Scientific World Journal

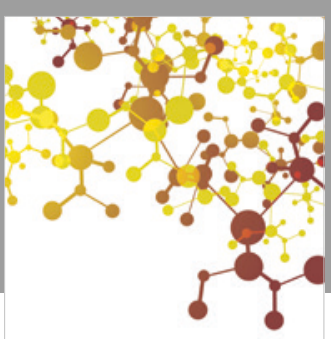

Journal of

Applied Chemistry
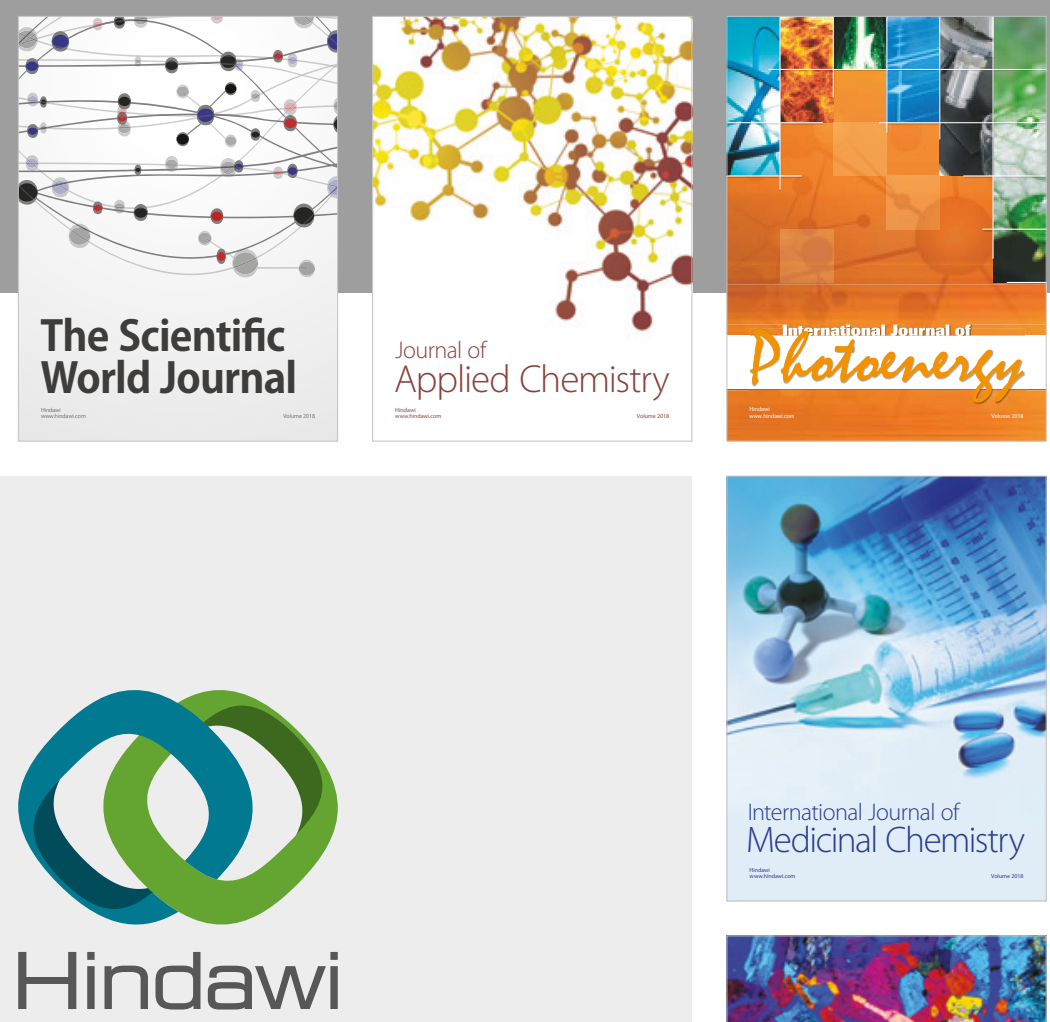

Submit your manuscripts at

www.hindawi.com
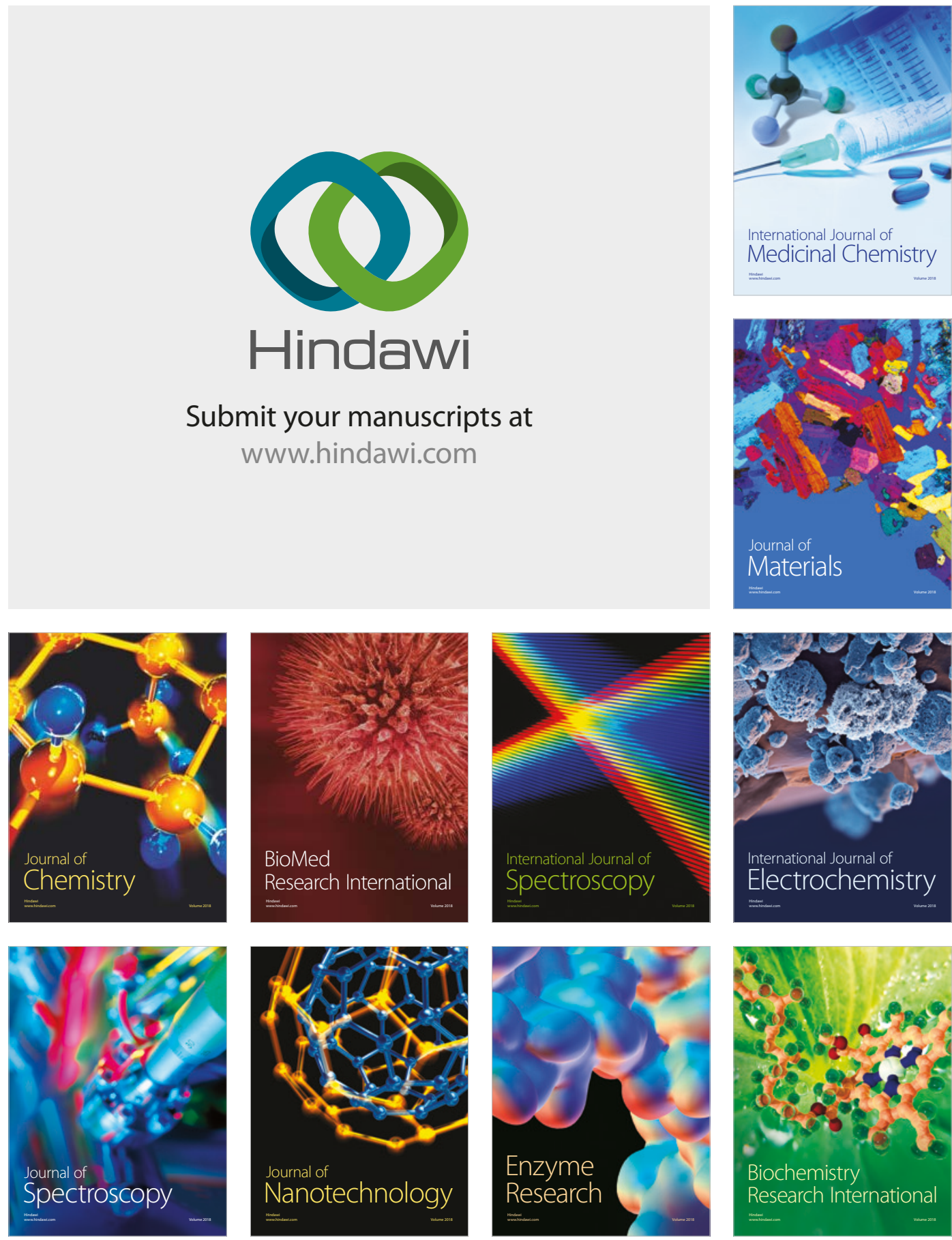
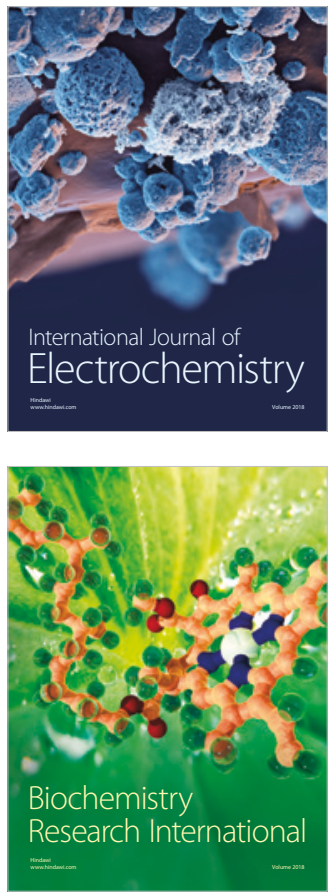